\title{
Stably stratified canopy flow in complex terrain
}

\author{
X. Xu ${ }^{1,2}$, C. $\mathbf{Y i}^{1,2,3}$, and E. Kutter ${ }^{1,2}$ \\ ${ }^{1}$ Queens College, City University of New York, Flushing, NY 11367, USA \\ ${ }^{2}$ The Graduate Center, City University of New York, New York, NY 10016, USA \\ ${ }^{3}$ Department of Meteorology, Bert Bolin Centre for Climate Research, Stockholm University, Stockholm 106 91, Sweden
}

Correspondence to: C. Yi (cyi@qc.cuny.edu)

Received: 04 September 2014 - Published in Atmos. Chem. Phys. Discuss.: 17 November 2014

Revised: 29 April 2015 - Accepted: 22 June 2015 - Published: 10 July 2015

\begin{abstract}
Stably stratified canopy flow in complex terrain has been considered a difficult condition for measuring net ecosystem-atmosphere exchanges of carbon, water vapor, and energy. A long-standing advection error in eddy-flux measurements is caused by stably stratified canopy flow. Such a condition with strong thermal gradient and less turbulent air is also difficult for modeling. To understand the challenging atmospheric condition for eddy-flux measurements, we use the renormalized group (RNG) $k-\varepsilon$ turbulence model to investigate the main characteristics of stably stratified canopy flows in complex terrain. In this twodimensional simulation, we imposed persistent constant heat flux at ground surface and linearly increasing cooling rate in the upper-canopy layer, vertically varying dissipative force from canopy drag elements, buoyancy forcing induced from thermal stratification and the hill terrain. These strong boundary effects keep nonlinearity in the two-dimensional NavierStokes equations high enough to generate turbulent behavior. The fundamental characteristics of nighttime canopy flow over complex terrain measured by the small number of available multi-tower advection experiments can be reproduced by this numerical simulation, such as (1) unstable layer in the canopy and super-stable layers associated with flow decoupling in deep canopy and near the top of canopy; (2) sub-canopy drainage flow and drainage flow near the top of canopy in calm night; (3) upward momentum transfer in canopy, downward heat transfer in upper canopy and upward heat transfer in deep canopy; and (4) large buoyancy suppression and weak shear production in strong stability.
\end{abstract}

\section{Introduction}

Canopy flow occurring within and immediately above vegetation canopies plays a substantial role in regulating atmosphere-biosphere interaction. The canopy layer is an interface between land and atmosphere, in which most natural resources humans need are produced by biochemical reactions. Canopy flow influences those biochemical processes through the control of gas exchange between the vegetation and the atmosphere (e.g., influencing reaction rates by changing gas concentrations), heat exchanges (e.g., influencing reaction conditions by changing temperature), and momentum exchanges (e.g., changing turbulent mixing conditions). Better understanding of canopy flow behavior has many practical implications in accurately determining, for instance, terrestrial carbon sinks and sources (Sun et al., 2007), the fate of ozone within and above forested environments (Wolfe et al., 2011), forest fire spread rate (Cruz et al., 2005), bark beetle management (Edburg et al., 2010), and others.

The typical patterns of forest canopy turbulent flows are characterized by an S-shaped wind profile with an exponential Reynolds stress profile rather than the widely used logarithmic wind profile and constant Reynolds stress observed over bare ground (Yi, 2008). S-shaped wind profiles have been observed within forest canopies in numerous studies (Baldocchi and Meyers, 1988; Bergen, 1971; Fons, 1940; Lalic and Mihailovic, 2002; Landsberg and James, 1971; Lemon et al., 1970; Meyers and Paw U, 1986; Oliver, 1971; Shaw, 1977; Turnipseed et al., 2003; Yi et al., 2005; Queck and Bernhofer, 2010; Sypka and Starzak, 2013). The $\mathrm{S}$-shaped profile refers to a secondary wind maximum that is often observed within the trunk space of forests and a secondary minimum wind speed in the region of greatest 
foliage density. The features of S-shaped wind profiles imply that $K$ theory and mixing-length theory break down within a forest canopy layer (Denmead and Bradley, 1985; Yi, 2008). Particularly, the assumption of a constant mixinglength within a canopy is not consistent with the original mixing-length theory. This is because a mixing-length $\left(l_{\mathrm{m}}\right)$ must satisfy von Karman's rule (von Kármán, 1930; Schlichting, 1960; Tennekes and Lumley, 1972), which indicates that a mixing length is a function of velocity distribution (Schlichting, 1960), as

$l_{\mathrm{m}}=\kappa\left|\frac{\mathrm{d} U / \mathrm{d} z}{\mathrm{~d}^{2} U / \mathrm{d} z^{2}}\right|$,

where $\kappa$ is von Karman's constant, $U$ is wind speed, and $z$ is height within the canopy. The mixing length of the Sshaped velocity distribution is not constant, being minimum at the local extreme values of the wind profile $(\mathrm{d} U / \mathrm{d} z=$ $\left.0, \mathrm{~d}^{2} U / \mathrm{d} z^{2} \neq 0\right)$ and maximum at the inflection point of the wind profile $\left(\mathrm{d} U / \mathrm{d} z \neq 0, \mathrm{~d}^{2} U / \mathrm{d} z^{2}=0\right)$ (Wang and $\mathrm{Yi}$, 2012). A mixing-length that varies with height within canopy has been demonstrated by large-eddy simulations (Coceal et al., 2006; Ross, 2008) and by water tank experiments (Poggi and Katul, 2007a).

The features of S-shaped wind profiles also dictate the existence of super-stable layers near levels where wind speed is maximum (or minimum) and temperature inversion (temperature increasing with height) exists, leading the Richardson number $(R i)$ to be extremely large or infinity (Yi et al., 2005). A super-stable layer acts as a "lid" or "barrier" that separates fluid into two uncorrelated layers: (1) the lower layer between the ground and the super-stable layer, and (2) the upper layer above the super-stable layer. This canopy flow separation was verified by $\mathrm{SF}_{6}$ diffusion observations (Yi et al., 2005) and carbon isotope experiments (Schaeffer et al., 2008). The lower layer is sometimes called a "decoupled layer" (Alekseychik et al., 2013) that is shallow, usually within the trunk space of a forest. Because the superstable layer prohibits vertical exchanges, the decoupled layer channels air in the horizontal direction. The characteristics of the channeled air are highly dependent on soil conditions, containing a high concentration of soil respired $\mathrm{CO}_{2}$ and soil evaporated water vapor, and consisting of colder air cooled by radiative cooling at the ground surface (Schaeffer et al., 2008). The channeled air is sometimes termed "drainage flow", and is a common phenomenon in hilly terrains under stable atmospheric conditions, such as on calm and clear nights (Yi et al., 2005; Alekseychik et al., 2013). The drainage flow limits the accuracy of tower-based estimates of ecosystem-atmosphere exchanges of carbon, water, and energy. Sensors on the tower above the canopy cannot measure the fluxes conducted by drainage flow because the layer above the canopy is decoupled from the drainage flow by the isolating super-stable layer. This advection problem is a well-known issue that has not yet been solved using eddy-flux measurements (Goulden et al., 1996; Aubi- net et al., 2003; Staebler and Fitzjarrald, 2004; Sun et al., 2007; Yi et al., 2008; Montagnani et al., 2009; Feigenwinter et al., 2010; Aubinet and Feigenwinter, 2010; Queck and Bernhofer, 2010; Tóta et al., 2012; Siebicke et al., 2012).

The concept of a super-stable layer is useful in interpreting data associated with stratified canopy air (Schaeffer et al., 2008). However, stratified canopy flows over complex terrain are far too complex to be able to characterize considering only a super-stable layer. Canopy structure (quantified by leaf area density profile), terrain slope, and thermal stratification are three key parameters in understanding the details of stratified canopy flows over complex terrain. The thermal stratification plays a leading role in the development of pure sub-canopy drainage flows (Chen and $\mathrm{Yi}$, 2012): strong thermal stratification favors drainage flow development on gentle slopes, while weak or near-neutral stratification favors drainage flow development on steep slopes. We speculate that interaction between thermal stratification and terrain slopes and vegetation canopy may result in multiple super-stable layers. The complicated thermal and flow patterns cause difficulties in understanding the mechanisms and rates of exchange of mass and energy between the terrestrial biosphere and the atmosphere (Alekseychik et al., 2013; Burns et al., 2011; Yi et al., 2005).

In this paper, we attempt to use a computational fluid dynamics (CFD) technique to examine the micro-structure of stratified canopy flows to provide insight into the role of physical processes that govern drainage motion and its turbulent characteristics within canopy in complex terrain. There are many challenges to face when pursuing this goal. First, the mixing-length theory and $K$ theory that are widely used as closure approaches to momentum equations (Wilson et al., 1998; Pinard and Wilson, 2001; Ross and Vosper, 2005; Katul et al., 2006) have been shown to have questionable validity within a forest canopy layer both theoretically (Yi, 2008) and observationally (Denmead and Bradley, 1985). Second, the analytical model (Finnigan and Belcher, 2004) is limited to neutral condition and hills of gentle slope. The analytical model is developed based on the linearized perturbation theory for the flow over a rough hill (Jackson and Hunt, 1975), which assumes that the mean flow perturbations caused by the hill are small in comparison to the upwind flow. Poggi and Katul (2007b) and Ross and Vosper (2005) have shown that the analytical model fails to model the flow pattern on dense canopies on narrow hills. Third, even though turbulence closure models and large eddy simulation models have been used to simulate flow within and above the canopy in numerous published studies, most numerically reproduced canopy flow is confined to idealized cases: either neutral (Ross and Vosper, 2005; Dupont et al., 2008; Ross, 2008) or weakly unstable (Wang, 2010) atmospheric conditions, or flat terrain with a homogeneous and extensive canopy (Huang et al., 2009; Dupont et al., 2010).

Simulations of stratified canopy flow have received little consideration. This might be attributed to difficulties in nu- 
merical simulations arising from small scales of motion due to stratification (Basu et al., 2006), and complex interaction between wind and canopy drag elements (Graham and Meneveau, 2012). Large eddy simulation has been quite successful in producing turbulent flow and its related scalar transport in neutral and unstable cases (Shen and Leclerc, 1997; Wang, 2010; Mao et al., 2008). However, under stable conditions, due to flow stratification, the characteristic size of eddies becomes increasingly small with increasing atmospheric stability, which eventually imposes an additional burden on the large eddy simulation subgrid-scale (LES-SGS) models (Basu et al., 2010). If resolution is high enough, any turbulent flow can be simulated accurately by LES. In fact, given sufficiently fine resolution, LES becomes direct numerical simulation (DNS), demanding very fine spatial and temporal resolution (Galperin and Orszag, 1993), which is currently beyond the reach of available computational power.

In this paper, we employ the renormalized group (RNG) $k-\varepsilon$ turbulence model to investigate stably stratified canopy flows in complex terrain. The RNG $k-\varepsilon$ turbulence model was developed by Yakhot and Orszag (1986a) using the renormalized group methods and prescribes the turbulentlength scale related to transport of turbulent kinetic energy and dissipation rate (Yakhot and Orszag, 1986b; Smith and Reynolds, 1992). Compared to a standard $k-\varepsilon$ turbulence model, the numerically derived parameters are not subject to experimental adjustment in the RNG $k-\varepsilon$ turbulence model. The rate of strain term in the dissipate transport equation is important for treatment of flows in rapid distortion limit, e.g., separated flows and stagnated flows (Biswas, and Eswaram, 2002) which commonly occur in vegetated hilly terrain. The initial successes in applying the RNG $k-\varepsilon$ turbulence model to generate airflows in hilly terrain have been demonstrated by Kim and Patel (2000) and Xu and Yi (2013).

\section{Method}

\subsection{Numerical implementation}

The two dimensional computational domain extends over $1400 \mathrm{~m} \times 130 \mathrm{~m}$ in a Cartesian coordinate system, corresponding to $1200 \times 157$ grid intervals in the $x$ and $y$ directions. A single hill is $100 \mathrm{~m}$ long covered with a $15 \mathrm{~m}$ tall homogeneous forest canopy, which extends from $650 \mathrm{~m}$ of the domain in horizontal. The mesh spacing in both horizontal and vertical at the forested hill is $0.5 \mathrm{~m}$ and is stretched with a power law, starting with a grid spacing of $0.5 \mathrm{~m}$ throughout the canopy, with a larger grid spacing stretching outwards from the edge of the forest and the top of the canopy on the hill crest. The stretch power in both horizontal and vertical is 1.15. Ground surface roughness height is set to be $0.01 \mathrm{~m}$.

In this study, the topography is specified with a ridge-like sinusoidal hill, infinite in the unsimulated third dimension.
The shape function of the hill in 2-D is defined as

$H(x)=\frac{H}{2} \cos \left(\frac{\pi x}{2 L}\right)+\frac{H}{2}$,

where $H$ is the hill height, $L$ is the half-length scale (half of the hill width at mid-slope height), $x$ is longitudinal distance with $x=0$ at the center of the single hill. The variation of the slope $(H / L)$ is specified by changing $H$ with a constant $L=25 \mathrm{~m}$.

The porous canopy layer (canopy height $h=15 \mathrm{~m}$ ) is designed horizontally homogeneous along the slope. The leaf area density profile $a(z)$ is specified as values from observation of an actual forest (Yi et al., 2005) with the maximum leaf area density at about $8 \mathrm{~m}$. Leaf area index (LAI) is 3.3. The ambient temperature is $\theta_{0}(z)=\theta_{00}+\gamma z$, where $\theta_{00}=288 \mathrm{~K}$ is the potential temperature at $z=0, \gamma$ is ambient lapse rate, set to $-6{ }^{\circ} \mathrm{C} \mathrm{km}^{-1}$. The cooling rate at ground surface is set to $-15 \mathrm{~W} \mathrm{~m}^{-2}$. Since we are most interested in calm nighttime conditions, no wind in the domain is initially specified. The fixed pressure boundary condition (open boundary) is applied to lateral boundaries and top boundary, where the pressure is close to $0.0 \mathrm{~Pa}$, relative to the external pressure.

\subsection{Conservation of mass and momentum}

The flow is assumed to be steady and the Boussinesq approximation is applied. The mass, momentum, and energy balance equations in the canopy sub-layer can be written as

$$
\begin{aligned}
& \frac{\partial \bar{u}_{j}}{\partial x_{i}}=0, \\
& \bar{u}_{j} \frac{\partial \bar{u}_{i}}{\partial x_{j}}=-\frac{1}{\rho} \frac{\partial P_{*}}{\partial x_{i}}+v \frac{\partial^{2} \bar{u}_{i}}{\partial x_{i} x_{j}}-\frac{\partial}{\partial x_{j}}\left(\overline{u_{i}^{\prime} u_{j}^{\prime}}\right) \\
& \quad-g_{i} \beta\left(\bar{\theta}-\theta_{\infty}\right)-F_{\mathrm{D} i}, \\
& \bar{u}_{j} \frac{\partial \bar{\theta}}{\partial x_{j}}=\Gamma \frac{\partial^{2} \bar{\theta}}{\partial x_{i} x_{j}}-\frac{\partial}{\partial x_{j}}\left(\overline{\theta^{\prime} u_{j}^{\prime}}\right)+\frac{1}{\rho c_{p}} Q_{\text {source }},
\end{aligned}
$$

where $\bar{u}_{i}$ and $\bar{u}_{j}$ are the mean velocity components along $x_{i}$ and $x_{j}$ direction, respectively; $\bar{\theta}$ is the mean potential temperature; $u_{i}^{\prime}, u_{j}^{\prime}$, and $\theta^{\prime}$ are the fluctuations from their mean value $\bar{u}_{i}, \bar{u}_{j}$, and $\bar{\theta} ; \rho$ is the air density; $v$ is kinematic viscosity of air; $P_{*}$ is the deviation of pressure from its reference value; $\beta$ is the thermal expansion coefficient of air; $\theta_{\infty}$ is the reference temperature; $g_{i}$ is the gravity acceleration in $i$ direction; $\Gamma=v / P r$ is thermal diffusion coefficient; and turbulent Prandtl number $P r$ is 0.5 in canopy layer and 1 above the canopy. $\operatorname{Pr}=0.5$ is close to the values used in large-eddy simulations of stably stratified atmospheric boundary layer turbulence (Basu and Porté-Agel, 2006; Stoll and Porté-Agel, 2008). In most of the region above the canopy (except very near the top of canopy), turbulence is very weak. In this region, molecular effects are dominant, especially in conditions without synoptic wind. $Q_{\text {source }}$ 
is the energy source. When the atmosphere is stably stratified, $Q_{\text {source }}<0$ indicating radiative cooling of the canopy elements and ground surface. The constant cooling rate at the surface can drive a steady-state stable boundary layer on flat and sloped terrain (Brost and Wyngaard, 1978), so we set $Q_{\text {source }}=0$ in the lower-canopy layer $(0-8 \mathrm{~m})$ and then linearly decreased to $-8 \mathrm{~W} \mathrm{~m}^{-3}$ at the top-canopy layer. The thermal conditions are sufficient to drive fully developed turbulent flows, according to dimensional analysis of the bulk Reynolds number:

$R e_{\mathrm{b}}=\frac{h_{i} U}{v}=\frac{O\left(10^{1} \mathrm{~m}\right) \times O\left(10^{-1} \mathrm{~m} \mathrm{~s}^{-1}\right)}{O\left(10^{-5} \mathrm{~m}^{2} \mathrm{~s}^{-1}\right)}=O\left(10^{5}\right)$,

where $h_{i}$ is the depth of boundary layer, $U$ is bulk velocity, and $v$ is kinematic viscosity.

The steady-state assumption is satisfied with condition proposed by Mahrt (1982):

$F \hat{H} / \hat{T} \ll 1$,

where $F$ is the Froude number, $\hat{H}$ is the ratio of the average flow depth $H$ to the surface elevation drop $\Delta Z_{\mathrm{s}}$, and $\hat{T}$ is the ratio of the timescale $T$ to the Lagrangian time $L / U$. The Froude number is defined as

$F=U^{2} /\left(g \frac{\Delta \theta}{\theta_{0}} H\right)$

where $U$ is downslope velocity scale $\left(=O\left(10^{-1}\right) \mathrm{ms}^{-1}\right), g$ is gravity acceleration $\left(=9.81 \mathrm{~m} \mathrm{~s}^{-2}\right), \Delta \theta$ is scale value for potential temperature deficit of the canopy layer $\left(=O\left(10^{0}\right) \mathrm{K}\right)$, $\theta_{0}$ is the basic state potential temperature $\left(=O\left(10^{2}\right) \mathrm{K}\right)$, and $H$ is the flow depth scale, chosen to be the depth of significant temperature deficit which coincides with the layer of enhanced thermal stratification $\left(=O\left(10^{1}\right) \mathrm{m}\right)$. In this simulation setting, $F=O\left(10^{-2}\right) . \hat{H}=H / \Delta Z_{\mathrm{s}}$, where $\Delta Z_{\mathrm{s}}=L \sin \alpha, L$ is downslope-length scale $\left(=O\left(10^{1}\right) \mathrm{m}\right)$, $\sin \alpha(\%)=O\left(10^{1}\right)$; thus, $\hat{H}=O\left(10^{0}\right) . \hat{T}=T U / L$, where $T=O\left(10^{4}\right) \mathrm{s}$ is suggested by Mahrt (1982) to represent the order of magnitude of temporal accelerations associated with the diurnal evolution of drainage circulations. In our simulation, $\hat{T}=O\left(10^{2}\right)$; thus, $F \hat{H} / \hat{T}=O\left(10^{-4}\right) \ll 1$.

$F_{\mathrm{D} i}$ is the drag force exerted by the canopy elements in $i$ direction:

$F_{\mathrm{D} i}=\frac{1}{2} K_{\mathrm{r}} u_{i}|U|$

where $K_{\mathrm{r}}$ is the resistance coefficient, which is derived from an empirical relationship given by Hoerner (1965):

$K_{\mathrm{r}}=\frac{1}{2}\left[\frac{3}{2 \phi}-1\right]^{2}$

where $\varphi$ is porosity of the canopy layer, which can be obtained from leaf area density profile $a(z)$ (Gross, 1993): $\phi(z)=\frac{\sqrt{1+4 a(z)}+1}{2 a(z)}$.

$F_{\mathrm{D} i}$ is zero above the canopy.

\subsection{RNG $k-\varepsilon$ model}

The RNG model was developed by Yakhot and Orszag (1986a, b; Yakhot et al., 1992) using RNG methods. The RNG $k-\varepsilon$ turbulent model has been successfully applied in reproducing topographic and canopy related flows (Kim and Patel, 2000; Xu and Yi, 2013; Pattanapol et al., 2007).

In RNG $k-\varepsilon$ model, the Reynolds stress in Eq. (3) and turbulent heat flux in Eq. (4) are solved by turbulent viscosity, as

$$
\begin{aligned}
-\overline{u_{i}^{\prime} u_{j}^{\prime}} & =\mu_{\mathrm{t}}\left(\frac{\partial \bar{u}_{i}}{\partial x_{j}}+\frac{\partial \bar{u}_{j}}{\partial x_{i}}\right)-\frac{2}{3} \delta_{i j} k, \\
-\overline{\theta^{\prime} u_{j}^{\prime}} & =\mu_{\theta} \frac{\partial \bar{\theta}}{\partial x_{j}}
\end{aligned}
$$

where $\mu_{\mathrm{t}}$ and $\mu_{\theta}=\mu_{\mathrm{t}} / \operatorname{Pr}$ are the turbulent viscosities of momentum and heat, respectively, $\delta_{i j}$ is Kronecker delta, and $k$ is the turbulent kinetic energy.

RNG $k-\varepsilon$ model assumes that turbulence viscosity in Eq. (10) is related to turbulence kinetic energy $k$ (TKE) and dissipation $\varepsilon$ :

$\mu_{\mathrm{t}}=\rho C_{\mu} \frac{k^{2}}{\varepsilon}$,

where $k$ and $\varepsilon$ are determined from the transport equations for $k$ and $\varepsilon ; C_{\mu}$ is a dimensionless constant.

The steady-state transport equations for $k$ and its dissipation $\varepsilon$ are written as

$\bar{u}_{i} \frac{\partial k}{\partial x_{i}}=\frac{\partial}{\partial x_{i}}\left(\frac{\mu_{\mathrm{t}}}{\sigma_{k}} \frac{\partial k}{\partial x_{i}}\right)+P_{\mathrm{s}}+P_{\mathrm{b}}+P_{\mathrm{w}}+T_{\mathrm{p}}-\varepsilon$,

$\bar{u}_{i} \frac{\partial \varepsilon}{\partial x_{i}}=\frac{\partial}{\partial x_{i}}\left(\frac{\mu_{\mathrm{t}}}{\sigma_{\varepsilon}} \frac{\partial \varepsilon}{\partial x_{i}}\right)+C_{\varepsilon} \frac{\varepsilon}{k} P_{\mathrm{s}}-\rho C_{\varepsilon} 2 \frac{\varepsilon^{2}}{k}-S$,

where $P_{\mathrm{s}}$ is shear production, given by

$P_{\mathrm{s}}=\mu_{\mathrm{t}} \frac{\partial \bar{u}_{i}}{\partial x_{j}}\left(\frac{\partial \bar{u}_{i}}{\partial x_{j}}+\frac{\partial \bar{u}_{j}}{\partial x_{i}}\right)$,

$P_{\mathrm{b}}$ is buoyancy production, given by

$P_{\mathrm{b}}=-\mu_{\theta} g_{i} \beta \frac{\partial \bar{\theta}}{\partial x_{i}}$.

$P_{\mathrm{w}}$ is wake production caused by canopy elements as (Meyers and Baldocchi, 1991)

$P_{\mathrm{w}}=\bar{u}_{i} F_{\mathrm{D} i}=\frac{1}{2} K_{\mathrm{r}}|U| \bar{u}_{i}^{2}$. 
$T_{\mathrm{p}}$ is pressure collection term, which is calculated as residual of other TKE components; $S$ is a volumetric source term which includes the rate-of-strain, given by

$S=\frac{C_{\eta} \eta^{3}\left(1-\frac{\eta}{\eta_{0}}\right) \varepsilon^{2}}{\left(1+\beta_{0} \eta^{3}\right) k}$,

$\eta=\frac{k}{\varepsilon}\left[\frac{P_{\mathrm{s}}}{\mu_{\mathrm{t}}}\right]^{1 / 2}$,

where the empirical constants $C_{\mu}, \sigma_{k}, \sigma_{\varepsilon}, C_{\varepsilon 1}, C_{\varepsilon 2}, \beta_{0}$, and $\eta_{0}$ are $0.0845,0.7194,0.7194,1.42,1.68,0.012$, and 4.38 , respectively (Yakhot and Orszag, 1986a, b).

\section{Results and discussion}

After a quasi-equilibrium condition is approached, all the solved fields in the studied cases are developed to be nearsymmetric horizontally (in the $x$ direction) with respect to the center of the modeled hill at $x=0$ due to the homogeneous boundary conditions and initial settings. We restrict our discussion to the right half of the hill. Our results show (Fig. 1) that wind structure is differentiated into down sweep $(H / L \leq 0.6)$ and updraft $(H / L \geq 0.8)$ within canopy. The temperature, wind, and turbulence characteristics on representative gentle $(H / L=0.6)$ and steep $(H / L=1.0)$ hills are illustrated (see Fig. 1) to explore the thermal and mechanical processes that govern the airflow structures.

\subsection{Thermal analysis}

In the model, strong stratification develops with distinct thermal distribution on the slope, subject to heat loss on the slope surface and the upper-canopy layer. The heterogeneous distribution of heat within the canopy causes a "fish-head"shaped temperature distribution on the slope, with the upper jaw in the upper-canopy layer and the lower jaw attaching to the slope surface. The jaws consist of cold air while the open mouth shows relatively warmer air (Fig. 2). In comparison with the upper jaw which is confined to the middle and lower slope, the lower jaw extends up to the crest of the hill. As the slope intensity is reduced, the fish-head effect's upper jaw is diminished. For a very gentle slope (i.e., $H / L \ll 1$ ), the model produces a horizontal isotherm pattern with cold air at the bottom of the slope and warm air upslope, as would be expected in real-world conditions. A significant difference in temperature distribution among varied slopes results in a different angle of orientation of the fish-head temperature profile. Isotherms are inclined parallel to the slope surface because they tend to follow the shape of the slope and the top-canopy layer since the cooling along the slope surface is uniform. The temperature distribution on a gentle hill is shown as an angled fish-head shape, while the fishhead is tilted by the slope on the steep hill, which is shown by the isotherms on the lower jaws. The different angle of

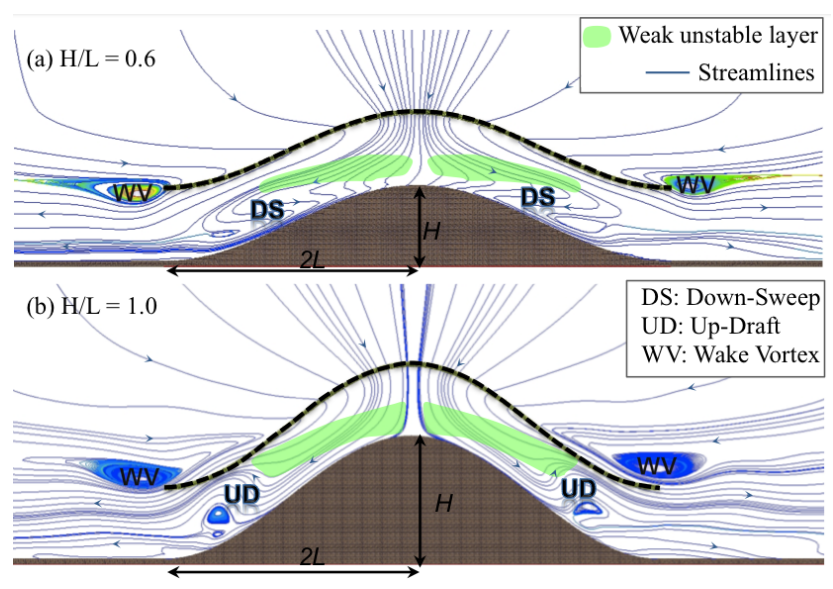

Figure 1. Simulated streamlines in the forested hill: (a) $H / L=0.6$; (b) $H / L=1.0$. The translucent green masks indicate the regimes with instability within the canopy. The top of the canopy is marked by black-dashed line. The black "WV" marks the region of wake vortices next to the edge of canopy. The "DS" in (a) and "UD" in (b) indicate the region of down-sweep wind and updraft wind on the gentle and steep slopes, respectively.

the fish-head profile can explain specific flow structures in the canopy (see Sect. 3.2). In accordance with the fish-head temperature distribution, temperature profiles are shown in three layers (Fig. 3a-d). A strong inversion layer is developed across the lower jaw, above which temperature slightly decreases with height in a thermal transition zone and a weak inversion layer is formed across the upper jaw. The temperature gradient and the depth of the lower inversion layer increases, since cold air flowing down the slope results in a cool pool on the lower slope where a single inversion layer extends above the canopy (Fig. 3e, f). The temperature difference from the hill surface to the top of the canopy at the hill crest is about 0.8 and $0.4^{\circ} \mathrm{C}$ for gentle and steep hills, respectively, while the difference increases to around $3.2^{\circ} \mathrm{C}$ in the canopy layer at the feet of both hills. The inversion strength near the surface is larger than in the upper canopy, which is due to the stronger radiative cooling effect on the surface. The temperature gradient and inversion on the steep hill are predicted weaker than on the gentle hill, because at the same horizontal $x / L$ location, the canopy layer is at a higher elevation on the steep hill. Regardless of the horizontal location $x / L$, we find that inversions both near the surface and in the upper canopy are stronger on the steep hill than on the gentle hill at the same elevation, which benefits the development of stronger drainage flow on the steep slope.

The $R i$ is the ratio of the relative importance of buoyant suppression to shear production of turbulence, which is used to indicate dynamic stability and formation of turbulence. $R i$ is calculated based on mean profiles of wind and temperature. For different purposes and data availability, gradient Richardson number $\left(R i_{g}\right)$ and bulk Richardson number $\left(R i_{\mathrm{b}}\right)$ 

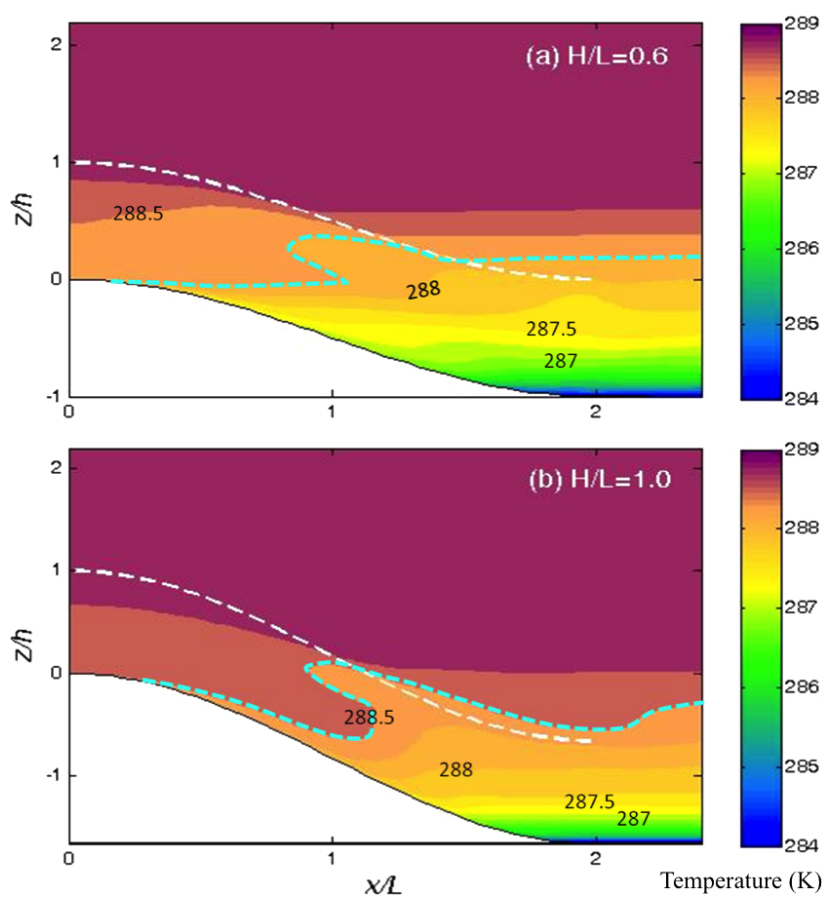

Figure 2. Contours of potential temperature $(\mathrm{K})$ along the right slope: (a) $H / L=0.6$; (b) $H / L=1.0$. The difference between isotherms is $0.25 \mathrm{~K}$. The numbers on isotherms indicate the temperature. The $x$ axis is normalized by the half-length scale of the hill $L$ and $y$ axis is normalized by the height of the canopy $h$. Whitedashed lines indicate the top of canopy and the isotherms marked with cyan-dashed lines highlight the "fish-head" temperature distribution.

are used to predict the stability within canopy. Yi et al. (2005) found that the $R i_{g}$,

$R i_{g}=\frac{(g / \bar{\theta})(\partial \bar{\theta} / \partial z)}{(\partial \bar{U} / \partial z)^{2}}$,

with $\partial \bar{U} / \partial z=0$ and $\partial \bar{\theta} / \partial z \neq 0$ at the inflection points of the S-shaped wind profile resulted in an infinite $R i_{g}$, which describes the super-stable layer. In a forest, wind and temperature are typically only measured in a few levels, making $\partial \bar{U} / \partial z$ and $\partial \bar{\theta} / \partial z$ impossible to directly calculate. Therefore, $R i_{\mathrm{b}}$ is commonly used to quantify stability between two levels $\left(z_{1}\right.$ and $\left.z_{2}\right)$ using the measured temperature and wind speed (Zhang et al., 2010; Burns et al., 2011; Alekseychik et al., 2013),

$R i_{\mathrm{b}}=\frac{g}{\bar{\theta}} \frac{\theta\left(z_{2}\right)-\theta\left(z_{1}\right)}{\left[U\left(z_{2}\right)-U\left(z_{1}\right)\right]^{2}}\left(z_{2}-z_{1}\right)$

In our modeling setting, the gridding space in vertical is $\Delta z=z_{2}-z_{1}$, which is $0.5 \mathrm{~m}$ in the canopy layer. We define a local Richardson number to evaluate stability around the

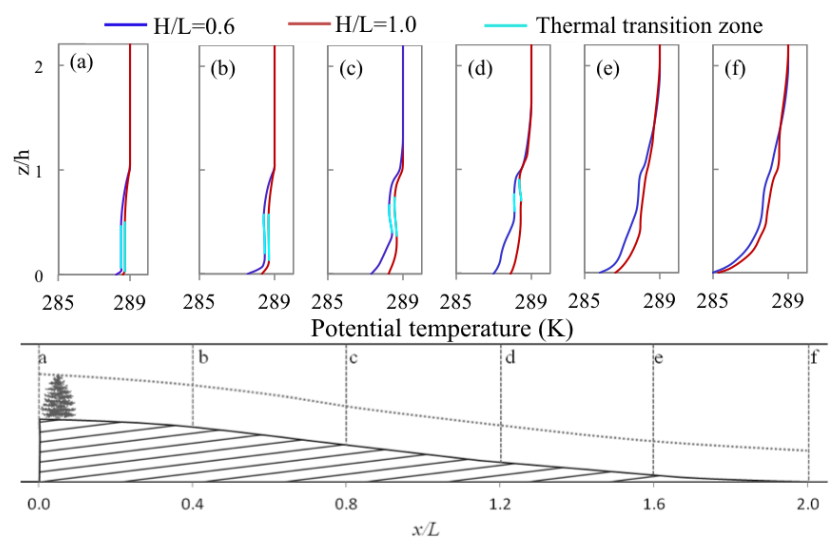

Figure 3. Potential temperature $(\mathrm{K})$ profiles on the slope for $H / L=0.6$ (blue) and $H / L=1.0$ (red). The locations of the six sections are labeled as (a)-(f), and their locations with respect to the hill are presented. Horizontal distances are normalized by the halflength scale $L$ of the hill. The cyan blue curves indicate the thermal transition zone with negative temperature gradient.

forested hill and examine the local stability in response to the heterogeneous distribution of heat. The local Richardson number in grid $(m, n)$ is calculated as,

$R i_{1}=\frac{g}{\theta_{m, n}} \frac{\left(\theta_{m, n}-\theta_{m, n-1}\right)\left(z_{m, n}-z_{m, n-1}\right)}{\left(u_{m, n}-u_{m, n-1}\right)^{2}+\left(w_{m, n}-w_{m, n-1}\right)^{2}}$.

The local Richardson number indicates that, within the canopy, flow is stably stratified except for an unstable region penetrating from the hill summit into the middle slope within the thermal transition regime (Fig. 1). $R i_{1}$ is found to be extremely large $\left(\sim 10^{5}\right)$ just above the canopy on the upper to middle slope (Fig. 4 locations a-d) indicating a thin primary super-stable layer just above the top of canopy. The primary super-stable layer is elevated and deepened on the lower slope (Fig. 4 locations e and f), extended from the height of 1.3-1.4 $h$ to about the height of $2 h$. The deep primary super-stable layer is caused by the strong cooling and temperature inversion at the base of the hill, regardless of slope intensity. Within canopy, a secondary super-stable layer with extremely high $R i_{1}$ is developed below $0.5 h$. On the lower slope, the depth of the secondary super-stable layer extends from the slope surface up to $0.5 h$. The deep secondary super-stable layer is consistent with deep and strong temperature inversion layer where wind is stagnated. The absence of a secondary super-stable layer on the summit could be explained by stronger mixing of warmer air from abovecanopy, because stronger drainage flow promotes the penetration of warm air from aloft when cold air moves down the slope (Zängl, 2003). Air in the transition region with negative temperature gradient is unstably stratified. The transition region is developed by the downwelling of cool air from the upper canopy with relatively warmer air upwelling from the lower canopy. The results show that for a sufficiently steep 

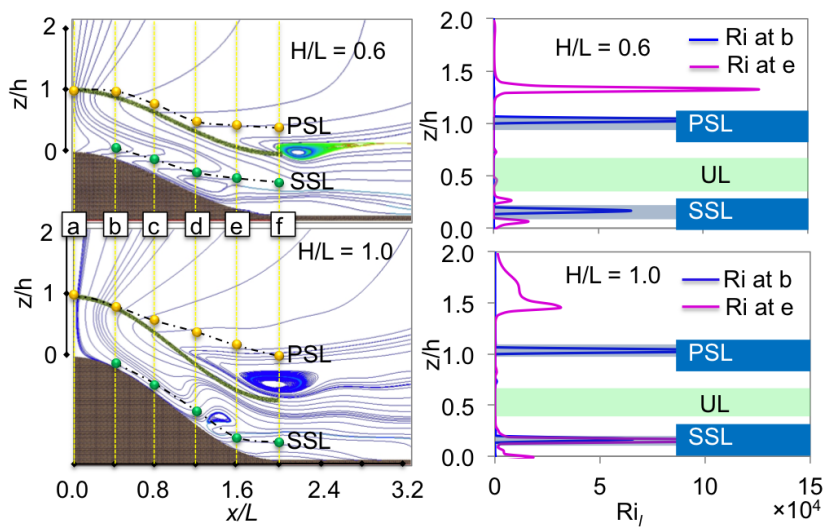

Figure 4. Locations of super-stable layers for $H / L=0.6$ and $H / L=1.0$ (left panel). The primary super-stable layers are marked by dash-dotted lines with yellow solid circles and secondary superstable layers are marked by dash-dotted lines with green solid circles. The Ri numbers at locations indicated by the yellow and green solid circles are extremely large, which are illustrated on the right panel for the locations (b) and (e). PSL denotes primary super-stable layer. SSL denotes secondary super-stable layer. UL denotes unstable layer.

slope, the effects of the hill dominate the atmospheric profile, while for more gentle slopes the effects of the canopy dominate the resultant atmospheric profile.

The nocturnal stable canopy layer could be used to explain the occurrence of within- and above-canopy flow decoupling observed in prior studies. van Gorsel et al. (2011) reported a very stable nighttime canopy layer $\left(R i_{\mathrm{b}}>1\right)$ using the bulk Richardson number, indicating that the canopy layer is decoupled from air aloft. Decoupling at the top of the canopy is more likely to occur as the buoyancy is more dominant and air at the top of the canopy is strongly stable. The canopy top decoupling weakens vertical exchange of mass and heat between the vegetation and the atmosphere aloft. The measurement data show large temperature and $\mathrm{CO}_{2}$ gradients (Burns et al., 2011) as decoupling occurs in a strongly stabilized atmosphere. Decoupling at the top of the canopy produced stronger carbon dioxide and temperature gradients than within-canopy decoupling (Alekseychik et al., 2013). The primary super-stable layer in our study is shown as a lid located at the top and above canopy, which could terminate the vertical exchange between the canopy and the air above. During nighttime, soil respiration contributes about 60-70\% (Janssens et al., 2001) of the total $\mathrm{CO}_{2}$ emission from the terrestrial ecosystem. The soil respired $\mathrm{CO}_{2}$ could be blocked by the secondary super-stable layer forming a very shallow pool on the slope surface.

\subsection{Wind flow structures}

Figure 1 shows that air above the canopy sinks and converges towards the hill and then shifts direction within the canopy.
Flow converges to the hill from all sides, and is then inflected near the top of the canopy. The height of inflection points increases as the air flows down the slope. The inflection points are approximately at the bottom of the primary super-stable layer. As a result of the abrupt convergence in the top of the canopy at the base of the hill, wake vortices are developed near the forest edge, after the wind leaves the hillside within the primary super-stable layer. The wake vortices can extend to about $2.6 L$ in horizontal and $1.3 h$ in vertical. According to the flow location within the canopy, we identify the drainage flow as two streams: the majority air mass within the upper-canopy inversion layer is called the upper-canopy drainage flow (UDF) layer, and the majority air mass within the inversion layer in the lower-canopy is called the lowercanopy drainage flow (LDF) layer. The UDF is developed as the air above the canopy sinks from lateral sides towards slopes of the hill. However, instead of further descending into the canopy, the sinking motion is diverted to follow the shape of the top-canopy layer as it reaches the top of the canopy (Figs. 1 and 6). The UDF accelerates down the slope between the top of the unstable layer and the bottom of the primary super-stable layer, reaching its maximum wind speed of 0.3 meters per second $\left(\mathrm{m} \mathrm{s}^{-1}\right)$ at location (Figs. $5 \mathrm{~d}$ and $6 \mathrm{a}$ ) on the gentle slope and $0.35 \mathrm{~m} \mathrm{~s}^{-1}$ at location (Figs. $5 \mathrm{e}$ and $6 \mathrm{~b}$ ) on the steep slope, and then decelerates down to the feet of the hills. The air sinking over the crest can directly reach the surface of the crest and flow along the slope to form the LDF. The maximum wind speed of the LDF is at location (Fig. 5d) for a gentle slope $\left(0.18 \mathrm{~m} \mathrm{~s}^{-1}\right)$ and at location (Fig. $5 \mathrm{c}$ ) for a steep slope $\left(0.29 \mathrm{~m} \mathrm{~s}^{-1}\right)$. The maximum wind speed in LDF occurs on the slope surface, below the secondary super-stable layer. Deceleration of the flow towards the base of the hill should occur for a number of reasons. The pool of cool, dense air at the base of the hill resists incoming flow. Also, the drag force acting against the wind is dependent on the speed of the air flow squared.

UDF and LDF show different patterns within canopy for different slopes, which essentially regulates the direction of wind shifting within canopy (Figs. 1 and 6). On the gentle slope $(H / L=0.6)$, UDF is much thicker compared with LDF (Fig. 6a). Air in UDF accelerates within the regime of the upper inversion layer reaching its maximum at the top of thermal transition region and then decelerates to a minimum ( $u=0$ and $w=0$, Fig. 5) at the top of the slope surface inversion layer. Then, UDF sweeps horizontally to join the shallow LDF on the slope surface, which is shown as negative streamwise velocity and near-zero vertical velocity in Fig. 5 (down-sweep). When the slope is steep $(H / L=1.0)$, UDF is much shallower than LDF on the upper slope. Air in LDF accelerates on the upper slope (Fig. 5a-c), followed by deceleration and stagnation. The stagnated flow jumps perpendicularly from the deep canopy layer to join the shallow UDF in the upper-canopy layer (the updraft, with $u>0$ and $w>0$, is visible in Figs. 1 and 5). The shifting winds on both gentle and steep slopes are parallel to the isotherms in the 

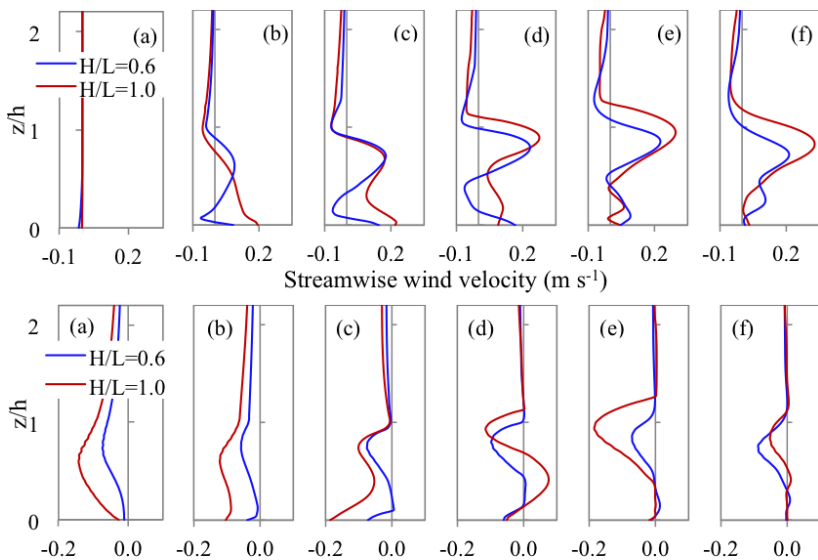
Streamwise wind velocity $\left(\mathrm{m} \mathrm{s}^{-1}\right)$

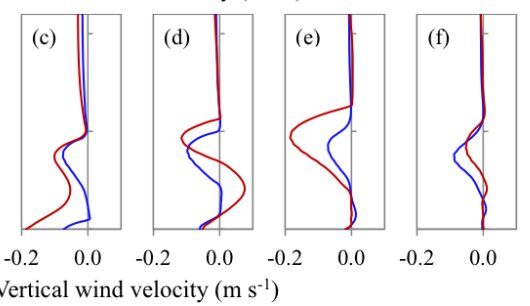

Figure 5. Profiles of streamwise velocity $\left(u ; \mathrm{m} \mathrm{s}^{-1}\right.$; top panel) and vertical velocity ( $w ; \mathrm{m} \mathrm{s}^{-1}$; bottom panel) for $H / L=0.6$ (blue) and $H / L=1.0$ (red). The locations of the six sections are labeled as (a)-(f), and their locations with respect to the hill are marked in Fig. 3 with the same letters. Note that wind velocity on the slope surface is not zero because the centers of bottom grid cells in the numerical calculation are not exactly at the surface.

warm and open fish-mouth region of the profile. Rotational vortices are formed below the shifting winds.

The generation and direction of the shifting-wind structure are primarily driven by the slope and stratification. Under calm and stably stratified conditions, the dominant driving force of sinking drainage flow on the slope is the hydrostatic buoyancy force which is given as $F_{\mathrm{hs}}=g\left(\Delta \theta / \theta_{0}\right) \sin \alpha$, where $\alpha$ is the slope angle, $\Delta \theta$ is the potential temperature difference between the ambient air and the colder slope flow, and $\theta_{0}$ is the ambient potential temperature. The drainage flow on both the gentle and steep slopes is initiated by the dominant $F_{\mathrm{hs}}$ as the air is calm and stably stratified (Froude number $\ll 1$; Belcher et al., 2008). The magnitude of $F_{\mathrm{hs}}$ increases with slope angle $\alpha$ so that $F_{\mathrm{hs}}$ is much larger on a steep slope than a gentle slope, leading to a stronger sinking motion above the crest. The sinking air penetrates to the lower part of the canopy at the hilltop. Thus, the LDF layer is deeper than the layer of UDF for a steep slope. However, the sinking motion above the crest on the gentle slope is diverted to follow the shape of the slope in the upper canopy due to smaller $F_{\mathrm{hs}}$, which is not strong enough to completely penetrate the canopy. As a result, UDF is deeper than the LDF on gentle slopes, in contrast to that on steep slopes. The heterogeneous cooling in the canopy layer causes two baroclinic zones consistent with the UDF and LDF: the upper-canopy layer and slope surface layer. The strong baroclinicity on the steep slope surface causes the deep LDF wind to rotate counterclockwise (i.e., turning upwards on the lower slope, perpendicular to the hill slope). However, the rotated wind is forced to shift down when hitting the top-canopy UDF. The wind at the baroclinic zone with a deep UDF on a gentle

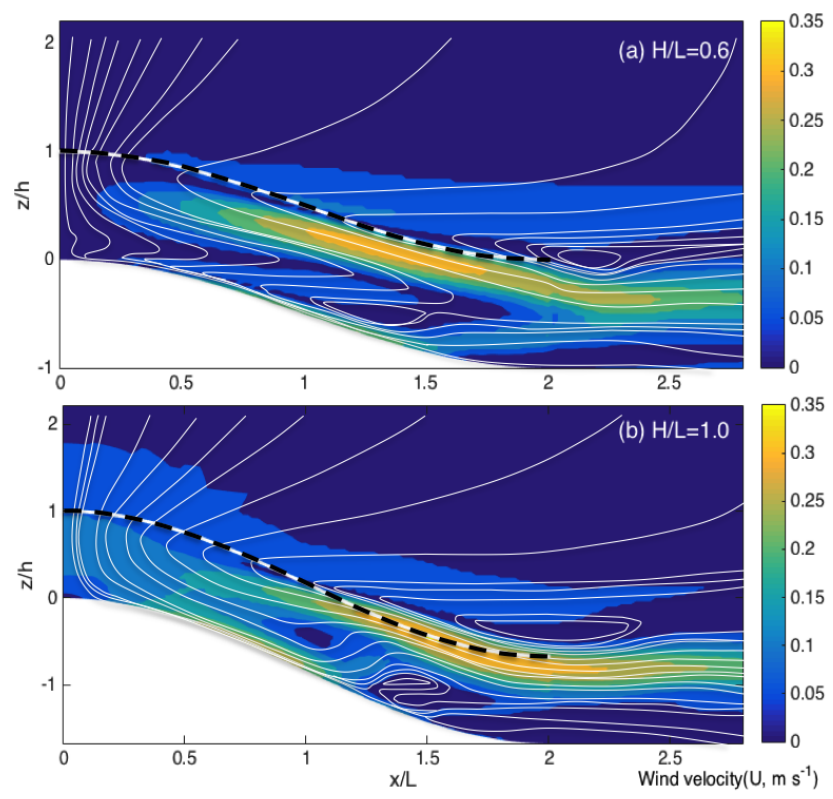

Figure 6. Wind velocity $\left(U, \mathrm{~m} \mathrm{~s}^{-1}\right)$ on the slopes for (a) $H / L=0.6$ and (b) $H / L=1.0$. The white solid lines are streamlines as shown in Fig. 1. The black-white-dashed lines denote the top of the canopy.

slope rotates clockwise, but shifts downslope when hitting the layer of the LDF.

\subsection{Turbulent fluxes of momentum and heat}

Figure 7 shows profiles of shear stress $\overline{u^{\prime} w^{\prime}}$. Shear stress is most significant in the region near the top of the canopy where wind impinges on the canopy resulting in strong wind shear. Another region of large shear stress is in the lower canopy. This is related to the wind shifts which lead to strong wind shear. Shear stress is small on the upper slope but increases down the slope. The maximum shear stress at the top of the canopy is located at the wake region (Fig. 7e, $\mathrm{f}$ ), where the wake vortices are formed. Shear stress is positive above the canopy indicating a downward transfer of momentum that is different from the usually observed downward transport of momentum in the upper canopy. It could be explained by the strong stability above the top of canopy, because strong stability substantially reduces the downward transport of momentum (Mahrt et al., 2000). The momentum transfer is reversed to upward $\left(\overline{u^{\prime} w^{\prime}}<0\right)$ when approaching the top of the canopy where airflow is diverted into canopy layer because of the UDF and shear production of turbulence. Strong upward momentum transfer near the top of canopy on the lower slope is associated with the wake generation behind the hill. In the upper canopy at mid-slope and downslope, shear stress decays rapidly as $z$ decreases, because of the momentum absorption by the dense crown. The upward momentum $\left(\overline{u^{\prime} w^{\prime}}<0\right)$ in the lower-canopy indicates momentum sources in the LDF on steep slope. The LDF was recognized 


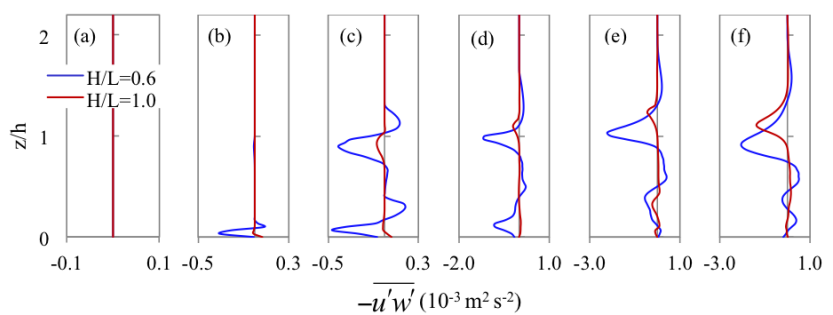

Figure 7. Profiles of shear stress, $\overline{u^{\prime} w^{\prime}}\left(10^{-3} \mathrm{~m}^{2} \mathrm{~s}^{-2}\right)$ on the slope for $H / L=0.6$ (blue) and $H / L=1.0$ (red). The locations of the six sections are labeled as (a)-(f), and their locations with respect to the hill are marked in Fig. 3 with the same letters.

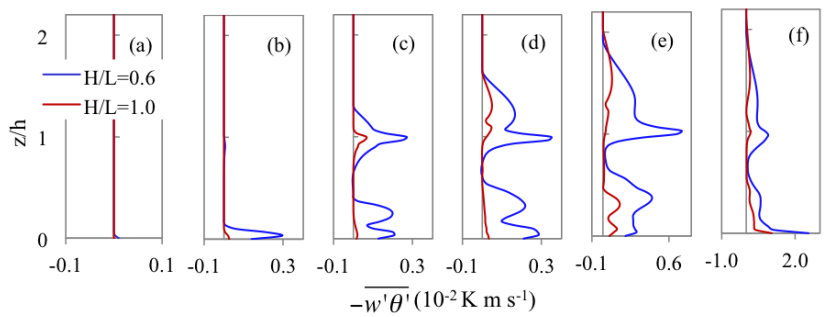

Figure 8. Profiles of turbulent heat flux, $-\overline{w^{\prime} \theta^{\prime}}\left(10^{-2} \mathrm{~K} \mathrm{~m} \mathrm{~s}^{-1}\right)$ on the slope for $H / L=0.6$ (blue) and $H / L=1.0$ (red). The locations of the six sections are labeled as (a)-(f), and their locations with respect to the hill are marked in Fig. 3 with the same letters.

as a jet-like flow in the lower canopy, which has important effects on momentum transfer within the canopy (Mao et al., 2007). Upward momentum transport in the canopy is very common, occurring in stable atmospheric conditions (Zhang et al., 2010). The opposite sign in momentum transfer near the slope surface on a steep and gentle slope can be explained by the strength of LDF on the slope.

The dominant positive turbulent heat flux, $-\overline{w^{\prime} \theta^{\prime}}$ indicates downward heat transfer above and within the canopy (Fig. 8). Heat transfer on the upper slope (Fig. 8a, b) is weak because the temperature difference between the canopy and the atmosphere above is small. The downward heat transfer is much stronger on the lower slope, where the air is cooled as a "cool pool" with the greatest temperature gradient. Turbulent heat flux increases towards the top of the canopy indicating increasing downward heat transfer $\left(-\overline{w^{\prime} \theta^{\prime}}>0\right)$ but the downward heat transfer decreases in the upper-canopy layer. The peak of turbulent heat flux near the top of the canopy is due to the strong radiative cooling in the upper canopy. Below that the near-zero and slightly upward turbulent heat flux (Fig. 8) is due to the near-neutral and negative temperature gradient in the thermal transition zone. As a result of the strong cooling in the ground surface, there are significant downward heat flux transfers in the lower canopy.
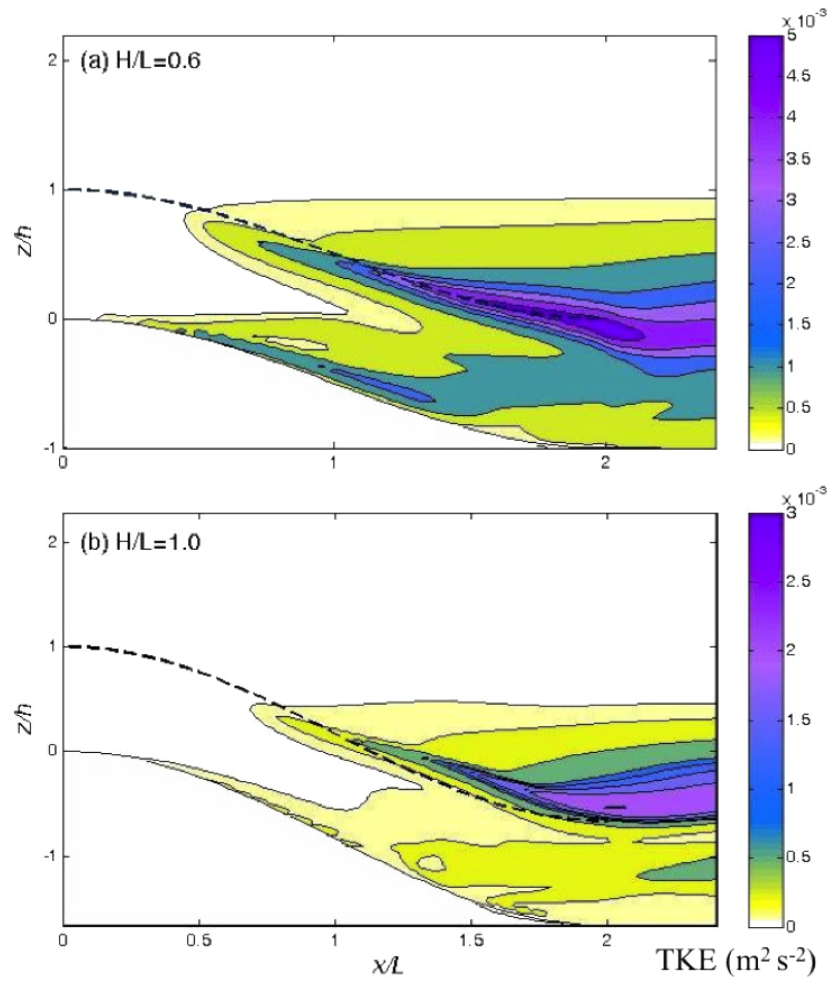

Figure 9. Contours of turbulent kinetic energy $\left(\mathrm{m}^{2} \mathrm{~s}^{-2}\right)$ : (a) $H / L=0.6$; (b) $H / L=1.0$. The black-dashed lines indicate the top of canopy.

\subsection{Turbulent kinetic energy budget}

In steady state, the TKE budget Eq. (13) can be written as

$0=T_{\mathrm{a}}+T_{\mathrm{t}}+T_{\mathrm{p}}+P_{\mathrm{s}}+P_{\mathrm{b}}+P_{\mathrm{w}}-\varepsilon$,

where $T_{\mathrm{a}}$ is the advection of TKE by the mean wind, $T_{\mathrm{t}}$ represents the turbulent transport of TKE, $T_{\mathrm{p}}$ represents the transport of TKE by pressure perturbation, $P_{\mathrm{S}}$ is the shear production of TKE, $P_{\mathrm{b}}$ is buoyancy production of TKE, $P_{\mathrm{w}}$ is wake production of TKE, and $\varepsilon$ is viscous dissipation of TKE. We calculate all the terms in the TKE budget equation individually except $T_{\mathrm{p}}$ which is treated as the residual of other terms.

TKE is examined to show the intensity of turbulence along the slope (Fig. 9). TKE is usually low within the canopy implying a low turbulence flow under strongly stable atmospheric conditions. TKE is available near the top of canopy on the mid-slope and downslope. The region with strongly shifting winds is on the lower slope where the wind shear is strong. The largest TKE is found in the region of wake vortices across the canopy edge. The TKE value is larger on the gentle slope than on the steep slope.

Contributions from transport and production terms of TKE are complicated. $P_{\mathrm{b}}$ is a principal sink of TKE under stable conditions (Figs. 10 and 11). $P_{\mathrm{b}}$ exhibits negative values near the top of the canopy and slope surface, where flow is stably stratified, which suppresses the turbulence around the 

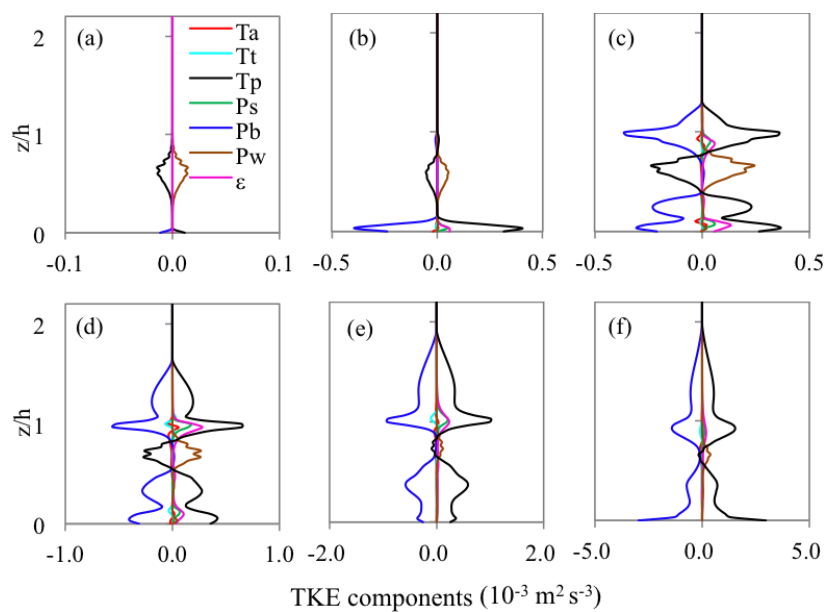

Figure 10. Profiles of TKE components $\left(10^{-3} \mathrm{~m}^{2} \mathrm{~s}^{-3}\right)$ for $H / L=0.6 . T_{\mathrm{a}}$ is the advection of TKE by the mean wind, $T_{\mathrm{t}}$ represents the turbulent transport of TKE, $T_{\mathrm{p}}$ represents the transport of TKE by pressure perturbation, $P_{\mathrm{S}}$ is the shear production of TKE, $P_{\mathrm{b}}$ is buoyancy production of TKE, $P_{\mathrm{W}}$ is wake production of TKE and $\varepsilon$ is viscous dissipation of TKE. The locations of the six sections are labeled as (a)-(f), and their locations with respect to the hill are marked in Fig. 3 with the same letters.

top of the canopy and within the deep canopy. In the thermal transition zone, the contribution of $P_{\mathrm{b}}$ is minimal $\left(P_{\mathrm{b}} \approx 0\right.$ or slightly positive). Buoyancy production is neglected in some studies because $P_{\mathrm{b}}$ is (1) unimportant compared with other terms in TKE budget (Lesnik, 1974) and (2) difficult to measure (Meyers and Baldocchi, 1991), restricting the modeling and measurement studies to near-neutral conditions. Shen and Leclerc (1997) showed that near the top of the canopy, the buoyancy production increases as instability increases, although it is smaller than $10 \%$ of shear production in unstable conditions. Leclerc et al. (1990) illustrated a strong positive correlation between buoyancy production and stability $\left(P_{\mathrm{b}}<0\right)$ or instability $\left(P_{\mathrm{b}}>0\right)$ both within and above the canopy, which is confirmed in our modeling results.

Wake production $\left(P_{\mathrm{w}}\right)$ is a principal source of TKE in the upper half of the canopy where the canopy is dense (i.e., for large values of $a$ and $K_{\mathrm{r}}$ ) on both steep and gentle slopes. Although the magnitude of $P_{\mathrm{w}}$ is very small on a steep slope, the relative contribution of $P_{\mathrm{w}}$ is very large in comparison with other TKE components. Even in the lower-canopy layer on the upper slope, $P_{\mathrm{w}}$ is a dominant source of TKE. This unusual phenomenon is induced by the deeper and stronger drainage flow on the slope surface.

The positive shear production $P_{\mathrm{s}}$ indicates the net transfer of kinetic energy from the mean flow to the turbulent component of the flow (Figs. 10 and 11). $P_{\mathrm{s}}$ is smaller than $P_{\mathrm{w}}$ except near the top of the canopy, which is consistent with the observations in soybeans (Meyers and Paw U, 1986), deciduous forests (Shi et al., 1987; Meyers and Baldocchi, 1991), and an artificial canopy (Raupach, 1987). $P_{\mathrm{s}}$ peaks at the top
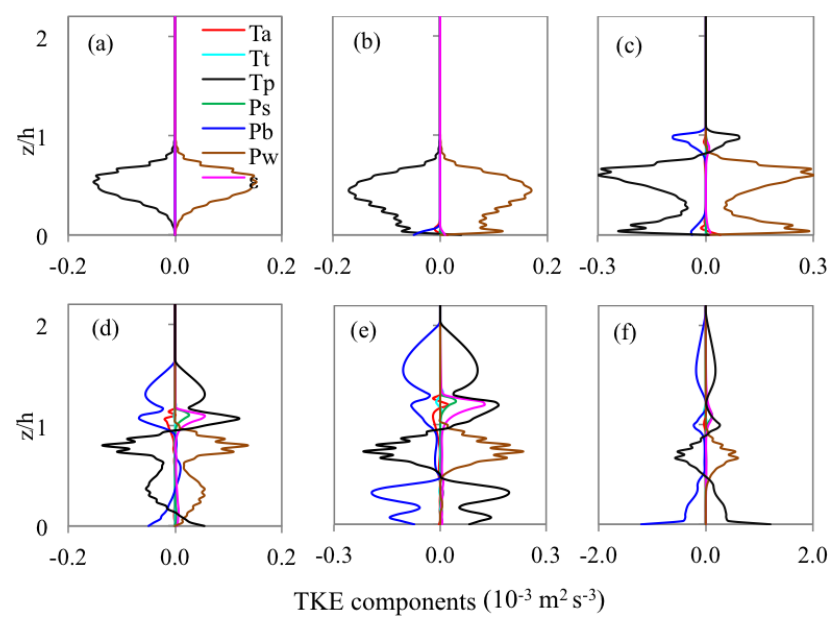

Figure 11. The same as in Fig. 10, but for $H / L=1.0$.

of the canopy, due to strong wind shear. Shear production is not as important as buoyancy and wake production in the canopy because of strong stability. Observational data also showed that shear production decreases with increasing stability in the lower two-thirds of the canopy (Leclerc et al., 1990).

Transport terms are the dominant source to maintain turbulent kinetic energy near the top of the canopy where strong buoyancy suppression occurs (Figs. 10 and 11). TKE is weakly transported by turbulence upward near the canopy top $\left(T_{\mathrm{t}}<0\right)$ and downward $\left(T_{\mathrm{t}}>0\right)$ in the canopy, because turbulence is limited by strong stability above the canopy. TKE transport by advection and turbulence is unimportant at all levels and all slopes in comparison to pressure transport. The field measurement of pressure transport $T_{\mathrm{p}}$ is difficult and the behavior of $T_{\mathrm{p}}$ in the TKE budget is uncertain (Raupach et al., 1996; Finnigan, 2000). Maitani and Seo (1985), Shaw et al. (1990) and Shaw and Zhang (1992) have confirmed that $T_{\mathrm{p}}$ is not small enough to be neglected according to the surface pressure measurements. Pressure diffusion is recognized as an important sink of TKE in the upper canopy and source of TKE below (Dwyer et al., 1997), under unstable conditions. Our results show that the contribution of pressure transport to the overall TKE budget is significant when it is identified as a residual of other TKE components. $T_{\mathrm{p}}$, which is of the same order as the production terms, supplies TKE in areas where the buoyancy suppression is very strong and extracts TKE where wake production is dominant. On gentle slopes, $T_{\mathrm{p}}$ is important for the compensation of TKE loss by buoyancy near the top of the canopy and in the lower part of the canopy, and it compensates TKE gain by wake motion in the upper half of the canopy (Fig. 10). On steep slopes, $T_{\mathrm{p}}$ on the lower half of the slope plays the same role as on gentle slopes to compensate the TKE loss by buoyancy and gain by wake (Fig. 11d-f), but the relative significance of wake production becomes more prominent. On the up- 
per slope (Fig. 11a-c), pressure transport is important in the whole canopy to work against wake production. Our results suggest that the pressure perturbation is stronger compared with other terms on steep slopes. In addition, thermal effects on the upper steep slope are diminished and the canopy effect is magnified since the air is warm and the temperature gradient is small on the elevated topography.

\section{Concluding remarks}

Stably stratified canopy flows in complex terrain are investigated by a RNG turbulent model, with emphasis on strong boundary effects, including persistent thermal forcing from ground and canopy elements, damping force from canopy drag elements, and buoyancy effects from temperature stratification and topographic character.

The fundamental characteristics of nighttime canopy flow over complex terrain are addressed by this numerical simulation as follows:

1. Multiple layering of thermal stratification. The stability around the canopy is characterized by stratification with super-stable layers above the top of the canopy and in the lower canopy, and an unstable layer within the canopy (Figs. 2, 3, 4).

2. Bifurcation of thermal-driven drainage flows. The drainage flow above the canopy is mainly driven by thermal stratification, being separated into two streams in the canopy: the upper-canopy drainage flow (UDF) layer and the lower-canopy drainage flow (LDF) layer (Figs. 1, 5, 6).

3. Buoyancy suppression of turbulence. The downward transport of momentum and heat flux in the canopy is reduced due to strong stability and reversed to be upward in the deep canopy (Figs. 7, 8). Buoyancy production suppresses turbulence significantly near the top of the canopy and in the deep canopy (Figs. 10, 11).

The thermal stratification and nocturnal drainage flows are interactive. The drainage flows, initiated by thermal stratification, result in the formation of super-stable layers. In addition, the drainage flows intensify the temperature inversion down the slope, thus intensifying the stability of super-stable layers. The properties of momentum and heat transfer may be related to the "shear-driven" and "buoyancy-driven" coherent structures that can lead to decoupling between the lower and upper canopy (Dupont and Patton, 2012). Although an unstable layer is more likely to occur during the foliated period (Dupont and Patton, 2012) and may only have influence on the small-scale motions within the canopy (Jacob et al., 1992), the super-stable layers associated with flow decoupling have direct influence on a larger scale soil, withinand above-canopy exchange processes (Alekseychik, et al., 2013).
The canopy flow behavior presented in Fig. 1 is expected to be measurable directly by multiple eddy-flux towers that are equipped with multi-level micrometeorological instruments (Feigenwinter et al., 2010; Baldocchi, 2008). Some turbulent exchange processes remain uncertain and require further study, including (i) how the varied vegetation structure, strength of background wind, and ambient stability influence the within-canopy stratification and turbulence, and (ii) how the complicated flows regulate scalar transfer within the canopy and scalar exchange between the vegetation and atmosphere aloft.

Acknowledgements. This research was supported, in part, under National Science Foundation Grants ATM-0930015, CNS0958379, and CNS-0855217, PSC-CUNY Research Awards (Enhanced) ENHC-42-64, and the City University of New York High Performance Computing Center. C. Yi is grateful to the International Meteorological Institute for supporting him as a Rossby Fellow to complete this work.

Edited by: X. Liu

\section{References}

Alekseychik, I., Mammarella, P., Launiainen, S., Rannik, Ü., and Vesala, T.: Evolution of the nocturnal decoupled layer in a pine forest canopy, Agr. Forest Meteorol., 174-175, 15-27, 2013.

Aubinet, M. and Feigenwinter, C.: Direct $\mathrm{CO}_{2}$ advection measurements and the night flux problem, Agr. Forest Meteorol., 150, 651-654, 2010.

Aubinet, M., Heinesch, B., and Yernaux, M.: Horizontal and vertical $\mathrm{CO}_{2}$ advection in a sloping forest, Bound.-Lay. Meteorol., 108, 397-417, 2003.

Baldocchi, D. D.: "Breathing" of the terrestrial biosphere: lessons learned from a global network of carbon dioxide flux measurement systems, Aust. J. Bot., 56, 1-26, 2008.

Baldocchi, D. D. and Meyers, T. P.: Turbulence structure in a deciduous forest, Bound.-Lay. Meteorol., 43, 345-364, 1998.

Basu, S. and Porté-Agel, F.: Large-eddy simulation of stably stratified atmospheric boundary layer turbulence. a scale dependent dynamic modeling approach, J. Atmos. Sci., 63, 2074-2091, 2006.

Basu, S., Porté-Agel, F., Foufoula-Georgiou, E., Vinuesa, J. F., and Pahlow, M.: Revisiting the local scaling hypothesis in stably stratified atmospheric boundary-layer turbulence. an integration of field and laboratory measurements with large-eddy simulations, Bound.-Lay. Meteorol., 119, 473-500, 2006.

Basu, S., Bosveld, F. C., and Holtslag, A. A. M.: Stable boundary layers with low-level jets. what did we learn from the LES intercomparison within GABLS3? The fifth international symposium on computational wind engineering (CWE2010), 23-27 May, Chapel Hill, NC, USA, 2010.

Belcher, S. E., Finnigan, J. J., and Harman, I. N.: Flows through forest canopies in complex terrain, Ecol. Appl., 18, 1436-1453, 2008.

Bergen, J. D.: Vertical profiles of wind speed in a pine stand, Forest Sci., 17, 314-322, 1971. 
Biswas, G. and Eswaram, V. (Eds.): Turbulent flows: Fundamentals, experiments and modeling, Narosa, 256 pp., 2002.

Brost, R. A. and Wyngaard, J. C.: A model study of the stably stratified planetary boundary layer, J. Atmos. Sci., 35, 1427-1440, 1978.

Burns, S. P., Sun, J., Lenschow, D. H., Oncley, S. P., Stephens, B. B., Yi C., Anderson, D. E., Hu, J., and Monson, R. K.: Atmospheric stability effects on wind fields and scalar mixing within and just above a subalpine forest in sloping terrain, Bound.-Lay. Meteorol., 138, 231-262, 2011.

Chen, H. and Yi, C.: Optimal control of katabatic flows within canopies, Q. J. Roy. Meteorol. Soc., 138, 1676-1680, doi:10.1002/qj.1904, 2012.

Coceal, O., Thomas, T. G., Castro, I. P., and Belcher, S. E.: Mean flow and turbulence statistics over groups of urban-like cubical obstacles, Bound.-Lay. Meteorol., 121, 491-519, 2006.

Cruz, M. G., Alexander, M. E., and Walimoto, R. H.: Development and testing of models for predicting crown fire rate of spread in conifer forest stands, Can. J. Forest Res., 35, 1626-1639, 2005.

Denmead, O. T. and Bradley, E. F.: Flux-gradient relationships in a forest canopy, in: The Forest-Atmosphere Interaction, edited by: Hutchison, B. A. and Hicks, B. B., 421-442, D. Reidel, Dordrecht, 1985.

Dupont, S. and Patton, E. G.: Momentum and scalar transport within a vegetation canopy following atmospheric stability and seasonal canopy changes: the CHATS experiment, Atmos. Chem. Phys., 12, 5913-5935, doi:10.5194/acp-12-5913-2012, 2012.

Dupont, S., Brunet, Y., and Finnigan, J. J.: Large-eddy simulation of turbulent flow over a forested hill: validation and coherent structure identification, Q. J. Roy. Meteor. Soc., 134, 1911-1929, 2008.

Dupont, S., Gosselin, F., Py, C., De Langere, E., Hemon, P., and Brunet, Y.: Modeling waving crops using large-eddy simulation: comparison with experiments and a linear stability analysis, J. Fluid Mech., 652, 5-44, 2010.

Dwyer, M. J., Patton, E. G., and Shaw, R. H.: Turbulent kinetic energy budgets from a large-eddy simulation of airflow above and within a forest canopy, Bound.-Lay. Meteorol., 84, 23-43, 1997.

Edburg, S. L., Allwine, G., Lamb, B., Stock, D., Thistle, H., Peterson, H., and Strom, B.: A simple model to predict scalar dispersion within a successively thinned loblolly pine canopy, J. Appl. Meteorol. Clim., 49, 1913-1926, 2010.

Feigenwinter, C., Montagnani, L., and Aubinet, M.: Plot-scale vertical and horizontal transport of $\mathrm{CO}_{2}$ modified by a persistent slope wind system in and above an alpine forest, Agr. Forest Meteorol., 150, 665-673, 2010.

Finnigan, J. J.: Turbulence in plant canopies, Annu. Rev. Fluid Mech., 32, 519-571, 2000.

Finnigan, J. J. and Belcher, S. E.: Flow over a hill covered by a plant canopy, Q. J. Roy. Meteor. Soc., 130, 1-29, 2004.

Fons, R. G.: Influence of forest cover on wind velocity, J. Forest, 38, 481-486, 1940.

Galperin, B. and Orszag, S. A.: Large Eddy Simulation of Complex Engineering and Geophysical Flows, Cambridge University Press, 622 pp., 1993.

Goulden, M. L., Munger, J. W., Fan, S. M., Daube, B. C., and Wofsy, S. C.: Measurements of carbon sequestration by long-term eddy covariance: methods and a critical evaluation of accuracy, Glob. Change Biol., 2, 169-182, 1996.
Graham, J. and Meneveau, C.: Modeling turbulent flow over fractal trees using renormalized numerical simulation: Alternate formulations and numerical experiments, Phys. Fluids, 24, 125105, doi:10.1063/1.4772074, 2012.

Gross, G.: Numerical Simulation of Canopy Flows, edited by: Douglas, J. and Marcus, M., Springer, Berlin, 167 pp., 1993.

Hoerner, S. F.: Fluid dynamic drag: practical information on aerodynamic drag and hydrodynamic resistence, Midland Park, NJ, 1965.

Huang, J., Cassiani, M., and Albertson, J. D.: The effects of vegetation density on coherent turbulent structures within the canopy sublayer: A large-eddy simulation study, Bound.-Lay. Meteorol., 133, 253-275, 2009.

Jackson, P. S. and Hunt, J. C. R.: Turbulent wind flow over a low hill, Q. J. Roy. Meteorol. Soc., 101, 929-999, 1975.

Jacobs, A. F. G., van Boxel, J. H., and Shaw, R. H.: The dependence of canopy layer turbulence on within-canopy thermal stratification, Agr. Forest Meteorol., 58, 247-256, 1992.

Janssens, I. A., Lankreijer, H., Matteucci, G., Kowalski, A. S., Buchmann, N., Epron, D., Pilegaard, K., Kutsch, W., Longdoz, B., Grünwald, T., Montagnani, L., Dore, S., Rebmann, C., Moors, E. J., Grelle, A., Rannik, Ü., Morgenstern, K., Oltchev, S., Clement, R., Gudmundsson, J., Minerbi, S., Berbigier, P., Ibrom, A., Moncrieff, J., Aubinet, M., Bernhofer, C., Jensen, N. O., Vesala, T., Granier, A., Schulze, E. D., Lindroth, A., Dolman, A. J., Jarvis, P. G., Ceulemans, R., and Valentini, R.: Productivity overshadows temperature in determining soil and ecosystem respiration across European forests, Glob. Change Biol., 7, 269 278, 2001.

Katul, G. G., Finnigan, J. J., Poggi, D., Leuning, R., and Belcher, S. E.: The influence of hilly terrain on canopy-atmospheric carbon dioxide exchange, Bound.-Lay. Meteorol., 118, 189-216, 2006.

Kim, H. G. and Patel, V. C.: Test of turbulence models for wind flow over terrain with separation and recirculation, Bound.-Lay. Meteorol., 94, 5-21, 2000.

Lalic, B. and Mihailovic, D. T.: A new approach in parameterization of momentum transport inside and above forest canopy under neutral conditions. Integrated Assessment and Decision Support, Proceedings of the1st biennial meeting of the International Environmental Modelling and Software Society, Switzerland, iEMSs, Manno, 139-154, 2002.

Landsberg, J. J. and James, G. B.: Wind profiles in plant canopies: studies on an analytical model, J. Appl. Ecol., 8, 729-741, 1971.

Leclerc, M. Y., Beissner, K. C., Shaw, R. H., den Hartog, G., and Neumann, H. H.: The influence of atmospheric stability on the budgets of the reynolds stress and turbulent kinetic energy within and above a deciduous forest, J. Appl. Meteorol., 29, 916-933, 1990.

Lemon, E., Allen, L. H., and Muller, L.: Carbon dioxide exchange of a tropical rain forest. 2, BioScience 20, 1054-1059, 1970.

Lesnik, G. E.: Results of measurement of turbulent energy balance components in a layer of vegetation, Izv. Atmos. Oceanic Phys., 10, 652-655, 1974.

Mahrt, L.: Momentum Balance of Gravity Flows, J. Atmos. Sci., 39, 2701-2711, 1982.

Mahrt, L., Lee, X., Black, A., Neumann, H., and Staebler, R. M.: Nocturnal mixing in a forest subcanopy, Agr. Forest Meteorol. 101, 67-78, 2000. 
Maitani, T. and Seo, T.: Estimates of velocity-pressure and velocitypressure gradient interactions in the surface layer over plant canopies, Bound.-Lay. Meteorol., 33, 51-60, 1985.

Mao, S., Feng, Z., and Michaelides, E. E.: Large-eddy simulation of low-level jet-like flow in a canopy, Environ. Fluid Mech., 7, 73-93, 2007.

Mao, S., Leclerc, M. Y., and Michaelides, E. E.: Passive scalar flux footprint analysis over horizontally inhomogenous plant canopy using large-eddy simulation, Atmos. Environ., 42, 5446-5458, 2008.

Meyers, T. P. and Baldocchi, D. D.: The budgets of turbulent kinetic energy and Reynolds stress within and above deciduous forest, Agr. Forest Meteorol., 53, 207-222, 1991.

Meyers, T. P. and Paw U, K. T.: Testing of a higher-order closure model for modeling airflow within and above plant canopies, Bound.-Lay. Meteorol., 37, 297-311, 1986.

Montagnani, L., Manca G., Canepa, E., Georgieva, E., Acosta, M., Feigenwinter, C., Janous, D., Kerschbaumer, G., Lindroth, A., Minach, L., Minerbi, S., Mölder, M., Pavelka, M., Seufert, G., Zeri, M., and Ziegler, W.: A new mass conservation approach to the study of $\mathrm{CO}_{2}$ advection in an alpine forest, J. Geophys. Res., 114, D07306, doi:10.1029/2008JD010650, 2009.

Oliver, H. R.: Wind profiles in and above a forest canopy, Q. J. Roy. Meteorol. Soc., 97, 548-553, 1971.

Pattanapol, W., Wakes, S. J., Hilton, M. J., and Dickinson, K. J. M.: Modeling of surface roughness for flow over a complex vegetated surface. World Acad, Sci. Eng. Technol., 26, 271-291, 2006.

Pinard, J. and Wilson, J. D.: First- and second-order closure models for wind in a plant canopy, J. Appl. Meteorol., 40, 1762-1768, 2001.

Poggi, D. and Katul, G. G.: The ejection-sweep cycle over gentle hills covered with bare and forested surfaces, Bound.-Lay. Meteorol., 122, 493-515, 2007a.

Poggi, D. and Katul, G. G.: An experimental investigation of the mean momentum budget inside dense canopies on narrow gentle hilly terrain, Agr. Forest Meteorol., 144, 1-13, $2007 \mathrm{~b}$.

Queck, R. and Bernhofer, C.: Constructing wind profiles in forests from limited measurements of wind and vegetation structure, Agr. Forest Meteorol., 150, 724-735, 2010.

Raupach, M. R.: A Lagrangian analysis of scalar transfer in vegetation canopies, Q. J. Roy. Meteorol. Soc., 113, 107-130, 1987.

Raupach, M. R., Finnigan, J. J., and Brunet, Y.: Coherent eddies and turbulence in vegetation canopies: The mixing-layer analogy, Bound.-Lay. Meteorol., 78, 351-382, 1996.

Ross, A. N.: Large-eddy simulation of flow over forested ridges, Bound.-Lay. Meteorol., 128, 59-76, 2008.

Ross, A. N. and Vosper, S. B.: Neutral turbulent flow over forested ridges, Q. J. Roy. Meteorol. Soc., 131, 1841-1862, 2005.

Schaeffer, S. M., Miller, J. B., Vaughn, B. H., White, J. W. C., and Bowling, D. R.: Long-term field performance of a tunable diode laser absorption spectrometer for analysis of carbon isotopes of $\mathrm{CO}_{2}$ in forest air, Atmos. Chem. Phys., 8, 5263-5277, doi:10.5194/acp-8-5263-2008, 2008.

Schlichting, H.: Boundary Layer Theory, 4th Edn., McGraw-Hill, 647 pp., 1960.

Shaw, R. H.: Secondary wind speed maxima inside plant canopies, J. Appl. Meteorol., 16, 514-521, 1977.

Shaw, R. H. and Zhang, X. J.: Evidence of pressure-forced flow in a forest, Bound.-Lay. Meteorol., 58, 47-64, 1992.
Shaw, R. H., Paw U, K. T., Zhang, X. J., Gao, W., Den Hartog, G., and Neumann, H. H.: Retrieval of turbulent pressure fluctuations at the ground surface beneath a forest, Bound.-Lay. Meteorol., 50, 319-338, 1990.

Shen, S. and Leclerc, M. Y.: Modeling the turbulence structure in the canopy layer, Agr. Forest Meteorol., 87, 3-25, 1997.

Shi, G., Shaw, R. H., Thurtell, G. W., den Hartog, G., and Neumann, H. H.: The turbulent kinetic energy budget within and above a deciduous forest. 18th Conf. on Agric. and For. Meteor., Boston, Am. Meteorol. Soc., 187-188, 1987.

Siebicke, L., Hunner, M., and Foken, T.: Aspects of $\mathrm{CO}_{2}$ advection measurements, Theor. Appl. Climatol., 109, 109-131, 2012.

Smith, L. M. and Reynolds, W. C.: On the Yakhot-Orszag Renormalization group method for deriving turbulence statistics and models, Phys. Fluids A, 4, 364-390, doi:10.1063/1.858310, 1992.

Staebler, R. M. and Fitzjarrald, D. R.: Observing subcanopy $\mathrm{CO}_{2}$ advection, Agr. Forest Meteorol., 12, 139-156, 2004.

Stoll, R. and Porté-Agel, F.: Large-eddy simulation of the stable atmospheric boundary layer using dynamic models with different averaging schemes, Bound.-Lay. Meteorol., 126, 1-28, 2008.

Sun, J., Burns, S. P., Delany, A. C., Oncley, S. P., Turnipseed, A. A., Stephens, B. B., Lenschow, D. H., LeMone, M. A., Monson, R. K., and Anderson, D. E.: $\mathrm{CO}_{2}$ transport over complex terrain, Agr. Forest. Meteorol., 145, 1-21, 2007.

Sypka, P. and Starzak, R.: Simplified, empirical model of wind speed profile under canopy of Istebna spruce stand in mountain valley, Agr. Forest Meteorol., 171-172, 220-233, 2013.

Tennekes, T. and Lumley, J. L.: A first course in turbulence, MIT, Cambridge, MA, 300 pp., 1972.

Tóta, J., Fitzjarrald, D. R., and da Silva Dias, M. A. F.: Amazon rainforest exchange of carbon and subcanopy air flow Manaus LBA site - a complex terrain condition, The Scientific World J., 2012, 165067, doi:10.1100/2012/165067, 2012.

Turnipseed, A. A., Anderson, D. E., Blanken, P. D., Baugh, W. M., and Monson, R. K.: Airflows and turbulent flux measurements in mountainous terrain Part 1. Canopy and local effects, Agr. Forest Meteorol., 119, 1-21, 2003.

van Gorsel, E., Harman, I. N., Finnigan, J. J., and Leuning, R.: Decoupling of air flow above and in plant canopies and gravity waves affect micrometeorological estimates of net scalar exchange, Agr. Forest Meteorol., 151, 927-933, 2011.

von Kármán, T.: Mechanische ähnlichkeit and yurbulenz, Nachr Ges Wiss Göettingen Math Phys. K1, 68, 58-76, 1930.

Wang, W.: The influence of topography on single-tower-based flux measurement under unstable condition: a modeling perspective, Theor. Appl. Climatol., 99, 125-138, 2010.

Wang, W. and Yi, C.: A new nonlinear analytical model for canopy flow over a forested hill, Theor. Appl. Climatol., 109, 549-563, 2012.

Wilson, J. D., Finnigan, J. J., and Raupach, M. R.: A first-order closure for disturbed plant-canopy flows, and its application to winds in a canopy on a ridge, Q. J. Roy. Meteorol. Soc., 124, 705-732, 1998.

Wolfe, G. M., Thornton, J. A., McKay, M., and Goldstein, A. H.: Forest-atmosphere exchange of ozone: sensitivity to very reactive biogenic VOC emissions and implications for incanopy photochemistry, Atmos. Chem. Phys., 11, 7875-7891, doi:10.5194/acp-11-7875-2011, 2011. 
$\mathrm{Xu}, \mathrm{X}$. and Yi, C.: The influence of geometry on recirculation and $\mathrm{CO}_{2}$ transport over forested hills, Meteorol. Atmos. Phys., 119, 187-196, 2013.

Yakhot, V. and Orszag, S. A.: Renormalization group analysis of turbulence: basic theory, J. Sci. Comput., 1, 3-61, 1986a.

Yakhot, V. and Orszag, S. A.: Renormalization group analysis of turbulence, Phys. Rev. Lett., 57, 1722-1724, 1986b.

Yakhot, V., Orszag, S. A., Thangam, S., Gatski, T. B., and Speziale, C. G.: Development of turbulence models for shear flows by a double expansion technique, Phys. of Fluids A, 4, 1510-1520, 1992.

Yi, C.: Momentum transfer within canopies, J. Appl. Meteorol. Clim., 47, 262-275, 2008.

Yi, C., Monsoon, R. K., Zhai, Z., Anderson, D. E., Lamb, B., Allwine, G., Turnipseed, A. A., and Burns, S. P.: Modeling and measuring the nocturnal drainage flow in a high-elevation, subalpine forest with complex terrain, J. Geophys. Res., 110, D22303, doi:10.1029/2005JD006282, 2005.
Yi, C., Anderson, D. E., Turnipseed, A. A., Burns, S. P., Aparks, J. P., Stannard, D. I., and Monson, R. K.: The contribution of advective fluxes to net eecosystem exchange in a high-elevation, subalpine forest, Ecol. Appl., 18, 1379-1390, 2008.

Zängl, G.: The impact of upstream blocking, drainage flow and the geostrophic pressure gradient on the persistence of cold-air pools, Q. J. Roy. Meteorol. Soc., 129, 117-137, 2003.

Zhang, G., Leclerc, M. Y., and Karipot, A.: Local flux-profile relationships of wind speed and temperature in a canopy layer in atmospheric stable conditions, Biogeosciences, 7, 3625-3636, doi:10.5194/bg-7-3625-2010, 2010. 